transition in the industrial structure. This internal migration is still going on. Rapidly expanding population and job centers characterized by many problems sprang up. At the same time other areas began to become deserted and gained serious unemployment problems.

A special characteristic of Finland is that the participation of women in the labor force has been one of the highest in the world. This factor has many connections with the maintenance of manpower policy. Perhaps the most central problem at the moment is how to guarantee the renewal of the population and, at the same time, the employment of women.

The most timely population and manpower question now is emigration. Not only does it exert pressure on our national economy, but, if it continues, it will signify quite a sharp drop in the size of the labor force in the $1980 \mathrm{~s}$. Will we be able to develop a social development policy with which we can prevent the kind of development currently underway?.

\title{
The Effects of Population Factors on Educational Planning
}

\author{
By ILPO KOKKO \\ Ministry of Education
}

Population factors and population policy goals form an important basis of educational planning. Endeavors to arrange the supply of educational services are being made according to generally accepted aims, so that citizens will have an equal opportunity to use educational services, regardless of means or place of residence, among other things. In accordance with this aim an attempt at equalizing the regional supply of educational services is being made, so that post-compulsory education would be available equally all over the country, corresponding to the average age group of schooling age.

Because educational policy is in many cases considered a means of achieving certain economical and regional policy goals and concurrently also certain population goals, in the past few years the active focus of educational planning has begun to be centered on directing vocational training and university level education so that it would support regional, economical and population development. In the following we will take a brief look at the effects of the goals mentioned here on today's educational planning.

\section{The effect of population development on the compulsory school}

The pupil admission need of the compulsory comprehensive school is affected mainly, by the number of children of compulsory school age and their regional 
distribution. Great changes have occurred in both of these in the last 25 years. In 1945 the number of children of compulsory school age (7-15-years-olds) was about 539000 , in 1960 it was about 838000 and in 1970 about 719000 . According to a forecast compiled by the Central Statistical Office the corresponding figure in 1980 would be about 668000 and in 1990 about 608000 . The variations in the size of the age groups in different communities and provinces have been even more clear-cut.

According to the statutes concerning the requirements for the functioning of schools, the comprehensive school districts must be drawn up so that the distance from a pupil's home to school is generally no longer than 5 kilometers. The school district can incorporate a larger area, if a suitable way can be found to arrange transportation and boarding for the pupils.

In Finland compulsory schools have almost always been small school units, because of the country's population and residential structure. About half of the elementary schools have always had only one or two teachers. Because small schools are generally situated in sparsely populated areas where the population base and the number of children being schooled declined sharply because of the drop in the birthrate and because of migration, many schools have been forced to close down since the 1950s. While there were still 819 schools in 1960 with only one teacher, the corresponding figure in 1975 was only 42 elementary or lower-stage comprehensive schools. According to a report made in the Ministry of Education almost 700 more small higher- and lowerstage comprehensive schools would have been forced to close down during the years 1975-83: if the statutes concerning the minimum number of pupils in sparsely inhabited communities would not have been changed last spring.

\section{Population development factors in post-compulsory school education.}

The legislation concerning general secondary education mentions that the criterion for founding new schools and parallel classes is the educational demand of the locality. Such a broad definition has not given the school authorities sufficient possibilities to properly regulate the quantitative development of education at the upper secondary school level. Because of the demand for education and because of the scarcity of secondary level vocational training, upper secondary school education has expanded in a manner inappropriate from the standpoint of educational policy. While the number beginning upper secondary school in 1950 corresponded to $9.4 \%$ of the 16 -year-old age group, in 1976 the 35430 pupils who began this schooling corresponded already to 45.6 percent. In conjunction with the growth in upper secondary level schooling a certain amount of regional equalization has taken place in educational opportunities. Apart from the largest (Uusimaa province 52.3) and the smallest (Ahvenanmaa province 34.6 ) percentages, the proportion of the 16-year-old age group in the other provinces beginning senior secondary school fluctuated between 38.9 percent and 46.5 percent in 1976. 
Because of the rapid expansion of upper secondary school education and the relatively slower increase in available further training meant for upper secondary school graduates, an ever-growing share of students who have matriculated from upper secondary school have had to seek admission to vocational training meant for graduates of the comprehensive school. Nowadays over one-third of the matriculating students are forced to choose a course of further study meant for non-matriculated students.

In the latest Ministry of Education intermediate-range plan and in the general grounds stated in the 1976 National budget the quantitative aim of upper secondary school education has been set as gauging upper secondary schooling in the long range, so that it will correspond to the supply of further education requiring matricultation from upper secondary school. According to a decision made by the Council of State in February 1977 the number of admissions to upper secondary school will be regulated, so that their share in the 16-year-old age group will not increase, not including a few possible regional exceptions of a temporary nature.

The law on vocational training institutes (1958) states, concerning the quantitative aims of vocational schooling, that the municipality must reserve a certain number of student admissions in relation to the number of inhabitants. Currently the municipalities, with a few rare exceptions, have fulfilled their legal obligations.

The school authorities feel that the quantitative aims of vocational training stated in the law are not sufficient. The intermediate-range plan for 1976-80 compiled in the Ministry of Education suggests that student admissions in the vocational training institutes should encompass $75 \%$ of the average age group. According to present plans this goal seems attainable by the middle of the next decade, partly as a result of the sharp decrease in the age group being schooled. The decrease in the age groups is very intense in the developing area provinces, where currently there is quite a lack of vocational school training. Because the problem cannot be solved merely by setting up permanent training for students, an abundant amount of so-called temporary student training, which does not require fixed investments, has been set up in the developing area provinces in addition to permanent student training. The setting up of temporary training is included in the program for attaining vocational training aims in the developing regions in 1976-79, made by the Council of State in February 1976. According to this program vocational training for about 6500 beginning students will be set up in the developing regions during the period covered by the program. The training of 3400 of these students will be on a temporary basis. This program is an attempt at equalizing regional access to educational services and at the same time creating the prerequisites for developing industrial activity in the developing regions.

The quantitative development of the universities is based on legislation enacted in 1966 concerning the universities and covering the years $1967-81$. The partial goals of the legislation have been attained for the year 1975. It is 
apparent, however, that the original aims cannot be attained by the year 1981, because of the national economic situation among other reasons. An amendment to the legislation is being prepared at the moment, according to which an attempt will be made to achieve the original aimes by the end of 1986 . A university system of the proposed size would at this time offer access to about $20 \%$ of the age group, while currently the corresponding figure is about $14 \%$.

During the past few decade significant regional equalization has taken place in the development of the university system. Except for the Pedagogical College in Jyväskylä, all of Finland's universities and colleges were situated in Helsinki or Turku up to the early 1950s. In 1960 only $6.2 \%$ of all university and college students were studying at universities and colleges not in Helsinki or Turku. In 1975 the corresponding figure had already risen to $35.8 \%$. It is the intention to continue to equalize the regional distribution of college-level training. The committee on the regional development of the university and college system (Committee report 1976:11) suggested that Finland be divided into seven collegiate areas, which would be formed according to the criteria of having a sufficient amount of population and sufficient population of schooling age and the possibility to create manifold study options covering different fields of learning. The aim is to create for each collegiate area a proportionately-sized quota of college-level training corresponding roughly to the schooling-age population.

\section{Education as a means of population policy}

As was noted earlier the equality principle of educational services has been interpreted in educational planning as meaning that an attempt will be made to offer the schooling-aged population of each area the same relative amount of various educational services taking into respect, however, regional variations caused by differences in the industrial structure. The regional unit used as a criterion varies in accordance with the form of school from a comprehensive school district covering part of one municipality to a collegiate area covering several provinces.

Earlier the general opinion was that educational services should be gauged according to the development of the population and of industry. As a result of the decline in the birthrate, emigration and internal migration and because of the radical transition which has taken place in the industrial structure, the age structure of the population and regional population development have become badly skewed. In addition to regional and industrial policy measures supporting areas with population loss the channeling of educational services has been seen as a way to have a favorable influence on regional industrial and population development. Lately proposed population and job forecasts encompassing regional and population policy aims are being used as a 
basis for schooling demand estimates instead of passive population and industrial forecasts. One must remember, however, that in addition to educational policy measures similarly directed placement and investment decisions made by enterprises and the measures of other national, regional and local administrative sectors are needed, so that the proposed effects would be realized.

The effects on population gained through educational policy are probably most clearly regional in effect. Educational policy also has effects extending to general population development, which appear indirectly, however. When educational opportunities improve an increasing number of young people of marriageable and childbearing age will participate in education, which may lower the birthrate if sufficient study and child care support is lacking. Growth in the proportion of students seems most likely in the near future, for in the legislation under reform concerning intermediate-level education the goal has been set to offer the opportunity to enter vocational training or general secondary education to every young person graduating from comprehensive school. The degree of participation in the labor market of trained women is higher than among the untrained, which may induce a lower birthrate.

Educational measures that can be seen as indirectly increasing the birthrate are compensation of expenses accrued by the schooling of children, of which perhaps the most significant measure implemented in the past few years is the realization by the end of this year of comprehensive education free-of charge to pupils. ${ }^{1}$ An attempt at increasing the equalization of costs through funds paid by society has occurred also in secondary- and college-level education. Currently under preparation is the proposition of arranging schooling for 6-year-olds. This reform can also be assumed to have possible favorable effects on the development of the birthrate.

\section{Regional Policy and Population Development}

\section{By OLAVI ÄNKÖ}

Office of the Council of State

The lack of balance in the regional population development of Finland increased markedly during the $1960 \mathrm{~s}$. This was caused mainly by swift and uncontrolled change in the industrial structure. Jobs in primary production diminished rapidly as a result of mechanization and other rationalization. Measures to further industrial production especially favored capital-intense production and thus also the intense concentration of production in the large centers of

1 The free-of-charge compulsory comprehensive school gradually introduced in this country consists of a six-year lower stage and a three-year higher stage. 